\title{
Development of a Novel Spectrophotometric Method Based on Diazotization- Coupling Reaction for Determination of Bisphenol A
}

\author{
Zhiqun Xu, Qiao Wu, Yunjian Duan, Meixia Yang, Minrui Ou and Xiaoping Xu* \\ Key Laboratory of Biopharmaceutical, College of Chemistry, Fuzhou University, \\ 350116 Fuzhou, P. R. China
}

\begin{abstract}
Bisphenol A (BPA) is an industrial material which can lead to endocrine disorders. In this work, a simple and sensitive spectrophotometric method for determination of BPA using diazotizationcoupling reaction was presented. To achieve the best performance of the developed method, the experimental parameters were optimized in terms of reagent concentration, reaction time, $\mathrm{pH}$, and temperature. Under the optimal conditions, the absorbance increased linearly with the increasing concentration of BPA in the range of $0.16-10.4 \mu \mathrm{g} \mathrm{mL}^{-1}$ with the correlation coefficient of 0.9991 and the detection limit of $0.05 \mu \mathrm{g} \mathrm{mL} \mathrm{m}^{-1}$. Results achieved with the spectrophotometric method were compared with those obtained using high performance liquid chromatography (HPLC) method. The proposed method was successfully applied to determine BPA in milk and water bottle samples and satisfactory results were obtained, which make it very suitable for routine analysis of BPA in quality control laboratories.
\end{abstract}

Keywords: bisphenol A, sulfamethoxazole, diazo-coupling reaction, food analysis

\section{Introduction}

Bisphenol A (BPA, 4,4-(propane-2,2-diyl)diphenol), one of important synthetic materials, is heavily used in plastic industry in the production of polymers mainly including polycarbonate (PC) plastics, epoxy resins and polysulfone resin. ${ }^{1-4}$ As the most widely used industrial compounds in the world, it can also be used in the production of plasticizer, flame retardant, antioxidant, heat stabilizer, rubber protective agent, pesticide, paint and other fine chemical products. ${ }^{5-7}$ Nowadays, the global amount of BPA and its products that are released into the environment annually is about 2000 tons. It is even more serious as BPA can migrate into food or food simulants from the resin or polymeric materials, especially upon heating or at high temperature. ${ }^{8}$ BPA is an environmental pollutant owing to its poor biodegradability. ${ }^{9}$ Low-dose exposure to BPA produces an increasing risk suffering from diabetes mellitus, at the same time with a variety of adverse effects on metabolic organs such as pancreas, adipose tissue and liver. ${ }^{10-13}$ Thus there is an urgent need to monitor the presence of BPA correlated to BPA-based food contact materials.

Up to now, various methods have been developed to detect BPA using traditional analytical methods ${ }^{14}$ such

*e-mail: xu@fzu.edu.cn as: liquid chromatography (LC), ${ }^{15,16}$ gas chromatography coupled with mass spectrometry (GC-MS) $)^{17,18}$ and enzymelinked immunosorbent assay. ${ }^{19}$ Although these methods present low detection limits and good selectivity for routine analysis, they require large capital investment, skilled operators, cumbersome sample preparation and pretreatment..$^{20,21}$ Recently, different types of analytical methods have also been studied, including fluorescent method, ${ }^{11,22}$ surface-enhanced Raman scattering, ${ }^{23}$ colorimetric methods, ${ }^{24}$ and electrochemical sensors. ${ }^{25,26}$ However, most of them suffer from complex chemical synthesis, the use of volatile organic solvents, high cost and so on. Therefore, these techniques are unsuitable for online or field monitoring.

In the recent years, spectrophotometric method has attracted more and more attention due to its simple operation, rapid response time, low cost, high sensitivity, potential for miniaturization, and capability of real sample analysis. ${ }^{27-29}$ A number of spectrophotometric methods have been used for various ions and drugs detection. For example, Cao et al. ${ }^{30}$ reported a simplified method based on ratio derivative ultraviolet spectrometry for simultaneous determination of BPA. The method provides a direct analysis of the samples without tedious sample preparation. The limits of detection was up to $3.5 \times 10^{-7} \mathrm{~mol} \mathrm{~L}^{-1}$ for BPA. However, this technique was relatively time-consuming 
because of the long time required for calculation prior to detection. Poorahong et al. ${ }^{31}$ developed a simple and high extraction efficiency online in-tube microextractor (ITME) assay for BPA detection in water samples. The ITME was fabricated by a stepwise electrodeposition of polyaniline, polyethylene glycol and polydimethylsiloxane composite (CPANI) inside a silico-steel tube. Under optimum conditions, the system provided a linear dynamic range of 0.1 to $100 \mu \mathrm{M}$ with a limit of detection of $20 \mathrm{nM}(\mathrm{S} / \mathrm{N} \geq 3)$.

The aim of this study was to develop an accurate selective and sensitive analytical method for the quantification of BPA in human food samples. In this paper, a new spectrophotometric method for rapid and sensitive determination of BPA was investigated. The diazo compound of sulfamethoxazole (SMZ) can react with BPA based on the diazotization-coupling reaction. The experimental parameters in terms of reagent concentration, reaction time, $\mathrm{pH}$, and temperature, etc. were optimized and a good linear relationship between the concentration of BPA and the intensity of the increased absorbance was obtained. We also introduced the fabrication of test strips for the sensitively determination of BPA in order to facilitate the adoption of our methodology by end users. Finally, the applicability of the proposed spectrophotometric method was compared with the high performance liquid chromatography (HPLC) method by analyzing the content of BPA in milk and water bottle samples and the results were satisfactory.

\section{Experimental}

\section{Chemicals and reagents}

All reagents and solvents were purchased from commercial suppliers and used without further purification unless otherwise stated. Deionized water was used throughout all experiments. Sulfamethoxazole, BPA were purchased from Sigma (St. Louis, USA). The sodium nitrite, hydrochloric acid, methanol, crystal violet lactone $(\mathrm{CVL}), \mathrm{K}_{4} \mathrm{Fe}(\mathrm{CN})_{6} \cdot 3 \mathrm{H}_{2} \mathrm{O}, \mathrm{ZnSO}_{4} .7 \mathrm{H}_{2} \mathrm{O}$ and sodium hydroxide used were purchased from Aladdin (Shanghai, China). The solution of metal ions were prepared from their nitrate salts or chloride salts of analytical grade. Stock solutions and mobile phases were prepared in ultrapure water and filtered through $0.45 \mu \mathrm{m}$ nylon membranes.

\section{Measurements}

UV-Vis absorption spectra were recorded on a U-4100 spectrophotometer. HPLC was performed with an Agilent 1100 chromatograph (Agilent Technologies, Santa Clara,
CA, USA) equipped with a UV detector operated at $278 \mathrm{~nm}$. All pH measurements were made with a Model PHS-3C meter.

\section{Sample preparation}

$1 \mathrm{~mL}$ sulfamethoxazole of known concentration was added to a mixture of solutions containing $6.4 \times 10^{-2} \mathrm{~mol} \mathrm{~L}^{-1}$ $\mathrm{HCl}$ and $28.0 \mu \mathrm{g} \mathrm{mL}^{-1} \mathrm{NaNO}_{2}$. Then the solution was shaken thoroughly for $3 \mathrm{~min}$ to allow the diazotization reaction to go to completion and contained in $0{ }^{\circ} \mathrm{C}$ for $10 \mathrm{~min}$ because it is very exothermic. In the following, the mixture was transferred into another $10 \mathrm{~mL}$ volumetric flask, which contained $9.2 \mu \mathrm{g} \mathrm{mL}-1$ of BPA. The mixture was shaken thoroughly for $5 \mathrm{~min}$, then a certain amount of $\mathrm{NaOH}$ $\left(9.4 \mathrm{mg} \mathrm{mL}^{-1}\right)$ was added into the volumetric flask and then filled to the mark with distilled water. After mixing well, the absorbance was measured in $1.00 \mathrm{~cm}$ quartz cells at $445 \mathrm{~nm}$, using distilled water as a reference. The absorbance of the reagent blank must be deducted from the sample. For the parameter optimization experiments, certain amounts of BPA were added to microcentrifuge tubes with different concentrations of $\mathrm{HCl}$, sulfamethoxazole, $\mathrm{NaNO}_{2}$, a different $\mathrm{pH}$ and reaction time.

\section{Analysis of milk and water bottle samples}

The sample solution was prepared according to the literature. ${ }^{32,33}$ Fresh liquid milk samples were purchased from a local Yonghui supermarket. $5.0 \mathrm{~mL}$ milk was first mixed with $10 \mathrm{~mL}$ anhydrous alcohol and a volume of $0.5 \mathrm{~mL}$ Carrez I $\left(15 \%, \mathrm{~m} / \mathrm{v}, \mathrm{K}_{4} \mathrm{Fe}(\mathrm{CN})_{6} .3 \mathrm{H}_{2} \mathrm{O}\right)$ and $0.5 \mathrm{~mL}$ Carrez II $\left(30 \%, \mathrm{~m} / \mathrm{v}, \mathrm{ZnSO}_{4} .7 \mathrm{H}_{2} \mathrm{O}\right)$ were added to eliminate the fatty compounds because lipids can affect the test results. The mixture was then centrifuged at $11000 \mathrm{rpm}$ for $10 \mathrm{~min}$ after $25 \mathrm{~min}$ sonication and 15 min shaking. Next, the supernatant was filtrated through a $0.45 \mu \mathrm{m}$ ultrafiltration membrane. The filtrate was collected and added into $25 \mathrm{~mL}$ volumetric flask, diluted with deionised water to the mark line. Recovery experiments were then carried out because the existing milk in the supermarket is free of BPA, and the sample was spiked with certain amounts of BPA standard solution directly. For the bottle samples, the samples were first washed with double distilled water thoroughly. Then, they were cut into small fragments of about $5 \times 5 \mathrm{~mm}$ in size and weighed accurately. The solutions containing water bottle fragments were ultrasonicextracted for $2 \mathrm{~h}$ in a water bath $\left(95 \pm 0.5^{\circ} \mathrm{C}\right)$. Then all the sample leaching solutions were cooled to room temperature, filtered with a $0.45 \mu \mathrm{m}$-filter membrane. At last, a certain amount of BPA standard solution was doped into these 
samples in order to investigate the recoveries of these water and plastic leaching solution samples.

\section{Results and Discussion}

\section{Reaction mechanism}

Aromatic amino compounds can react with sodium nitrite to form diazonium salt at low temperature. ${ }^{34}$ For SMZ, an embedded sulfo group was introduced to increase water solubility and electron-withdrawing property. BPA, which contained strong electron-donating group of hydroxyl, was chosen as the coupling compound in this study. Considering all of it, the diazo compounds and coupling compounds were preliminarily selected and the aromatic compounds which contained hydroxyl groups were used in the condition of alkalinity. In molecular structure, delocalized $\pi$ conjugated organic molecules was formed and the coplanar and big conjugate system had strong light-absorbing ability. The conjugates shows steady color of yellow and spectrophotometry method is further available to detect BPA content. The possible mechanism of the reaction can be simply described as the following Scheme 1 .

Diazo coupling reactions bring to the formation of colored substances named azo compounds. ${ }^{32}$ The azo compounds formed between diazotized sulfanilic acid and indole in aqueous solution have been early described in a spectrophotometric method. ${ }^{35,36}$ In our work, the development of the reaction occurs in two steps: firstly, the reaction of sulfamethoxazole (SMZ) with sodium nitrite occurs in an acid medium $(\mathrm{HCl})$ producing the diazo compound. Secondly, the diazo compound in alkaline medium coupled with the BPA produced a compound that was monitored at $445 \mathrm{~nm}$.

\section{The UV-Vis absorption spectrum}

The UV-Vis absorption spectra of BPA-SMZ in the absence and presence of BPA solutions were shown in
Figure 1. As can be seen from Figure 1, BPA has two absorbance peaks between 200 and $600 \mathrm{~nm}$. The first absorption peak at $225 \mathrm{~nm}$ is attributed to the influence of solvent absorbance. The second absorption peak at $278 \mathrm{~nm}$ was chosen as the detection wavelength for UV with HPLC detection. ${ }^{15,31}$ For SMZ, it also has a characteristic peak at $266 \mathrm{~nm}$ (Figure 1). The diazo coupling reaction between SMZ diazonium salt and BPA afforded a colored complex with an absorption maximum at $445 \mathrm{~nm}$. Water and methanol for SMZ and BPA were respectively used for all analyses. These selections were based on the solubility of the standards and the related analytes in the mentioned solvents (SMZ are easily dissolved in acidic or alkaline solution, meanwhile BPA are preferably dissolved in lowmedium polar organic solvents). As can be seen, when $4.6 \mu \mathrm{g} \mathrm{mL}{ }^{-1} \mathrm{BPA}$ were present, the peaks intensity increased about 2.1 times at $445 \mathrm{~nm}$ compared to the intensity of BPA $\left(9.2 \mu \mathrm{g} \mathrm{mL} \mathrm{m}^{-1}\right)$ at $278 \mathrm{~nm}$. The significant increase indicated a reaction occurred. Furthermore, maximum value around $445 \mathrm{~nm}$ has a relationship with concentrations of BPA to an extent.

\section{Conditions of optimization for BPA detection}

To achieve the best performance of the developed method, the experimental parameters were optimized in terms of reagent's concentration, reaction time, $\mathrm{pH}$, and temperature. Other conditions were remained constant during each optimization and the concentration of BPA is $4.6 \mu \mathrm{g} \mathrm{mL}^{-1}$ for the sensitive detection in the spectrophotometric system.

\section{Optimization for the diazotization reaction}

\section{Effect of $\mathrm{pH}$}

Low $\mathrm{pH}$ could increase the stability of the diazonium salt. As the sodium nitrite can easily and fully react with the aromatic primary amine because of the fast reaction rate in low $\mathrm{pH}, \mathrm{pH}$ of the system has a significant influence on
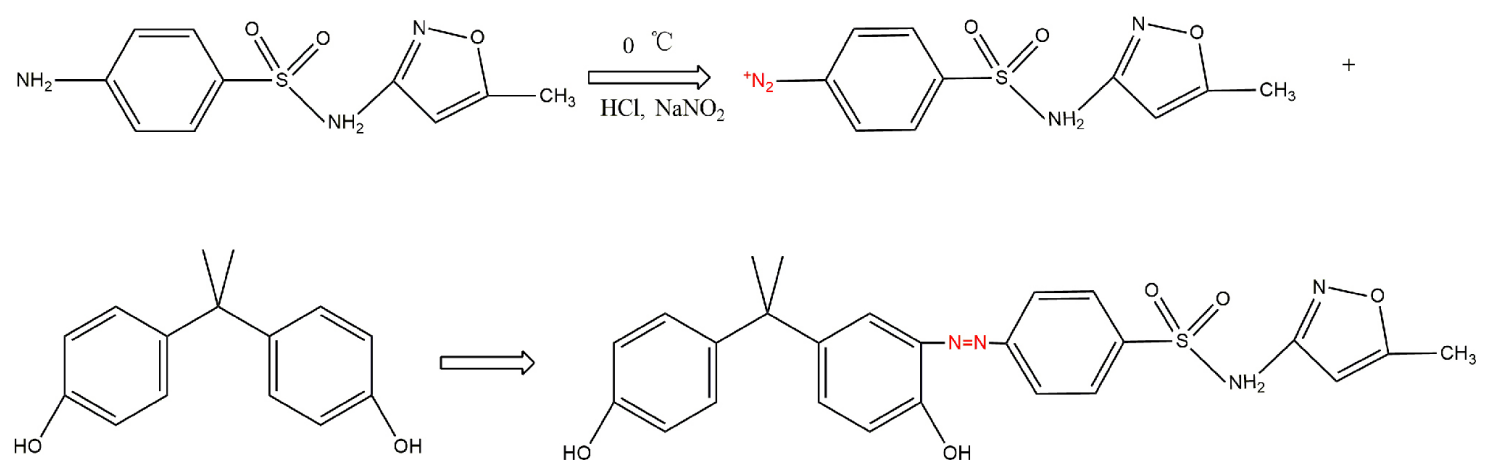

Scheme 1. Scheme demonstrating the composite diazotization-coupling reaction of SMZ and BPA. 

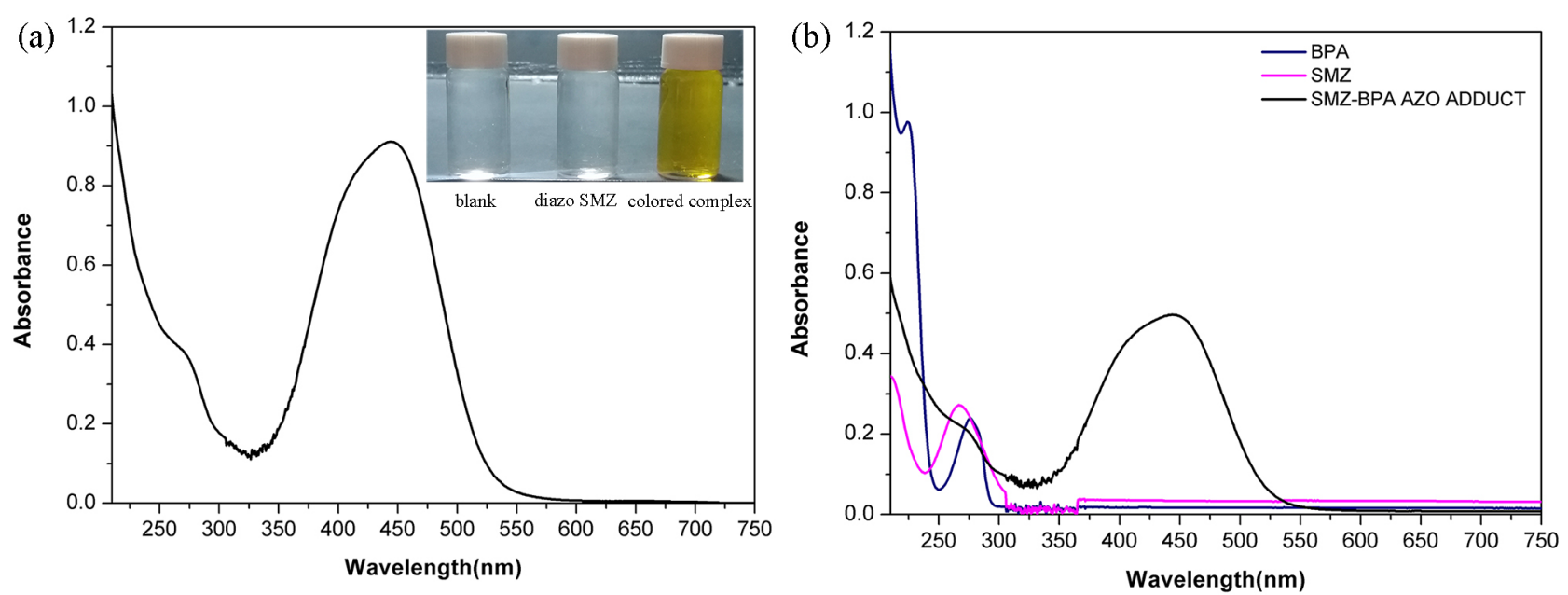

Figure 1. (a) UV-Vis absorption spectra of SMZ-BPA azo adduct. Insert: comparison of the blank (ultrapure water), diazo SMZ and SMZ-BPA azo adduct (colored complex); (b) UV-Vis absorption spectra of BPA, SMZ and SMZ-BPA azo adduct. BPA: $9.2 \mu \mathrm{g} \mathrm{mL}{ }^{-1}$, SMZ: $9.2 \mu \mathrm{g} \mathrm{mL}^{-1}$, SMZ-BPA azo adduct potency of $4.6 \mu \mathrm{g} \mathrm{mL}^{-1}$ BPA.

the diazotization of SMZ. Different volumes of $1 \mathrm{~mol} \mathrm{~L}^{-1}$ $\mathrm{HCl}$ were used to evaluate the effect of the concentration of the acid on the reaction medium. As shown in Figure 2, the absorbance vary gradually with the decrease of $\mathrm{pH}$ and reaches the maximum when $\mathrm{pH}$ is ca 1.2. Moreover, the absorbance was maximum and stable between 1.0 and 2.0. Therefore, $6.4 \times 10^{-2} \mathrm{~mol} \mathrm{~L}^{-1} \mathrm{HCl}$ was chosen as the acidic medium for the diazotization of SMZ. All measurements were carried out as triplicates.

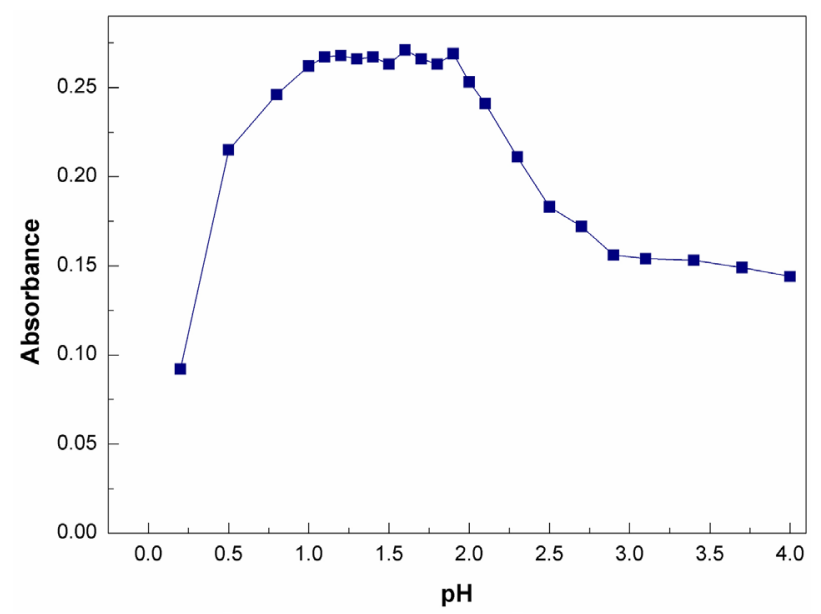

Figure 2. Effect of $\mathrm{pH}$ on the diazo reaction $(\mathrm{n}=3)$. Reaction time: $5 \mathrm{~min}$. SMZ: $9.6 \mu \mathrm{g} \mathrm{mL}-1$.

\section{Effect of time on the diazotization reaction}

The relation between the diazotization reaction time in the range of 1-25 min and the absorbance of the mixture solution was investigated. As the diazotization reaction time increased, the absorbance was also increasing. When it reacted for above $5 \mathrm{~min}$, the absorbance remained constant. So, 5 min was chosen as the diazotization reaction time (Figure 3).

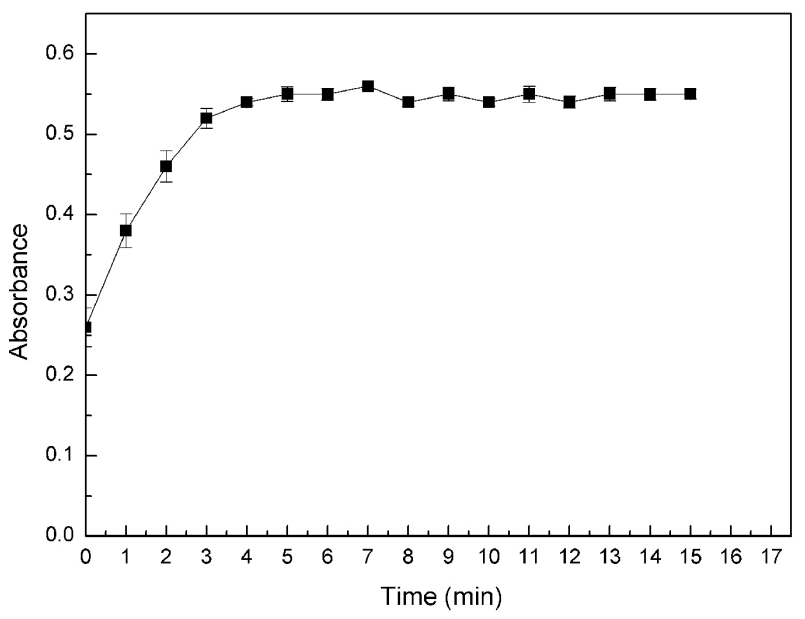

Figure 3. Effect of the diazotization reaction time on absorbance intensity. Results are the average of three consecutive determinations, which were obtained by processing sulfamethoxazole standard solution containing $19.2 \mu \mathrm{g} \mathrm{mL} \mathrm{L}^{-1}$.

\section{Effect of sodium nitrite concentration}

Sodium nitrite, as the diazotizing reagent in this system, plays an important role in diazotizing reaction. ${ }^{37}$ So the concentration of sodium nitrite solution varying from 10.0 to $40.0 \mu \mathrm{g} \mathrm{mL} \mathrm{m}^{-1}$ was investigated. The results demonstrated that the increase in absorbance tends to have a constant value for the sodium nitrite solution concentration equal to or higher than $28.0 \mu \mathrm{g} \mathrm{mL} \mathrm{m}^{-1}$, so this concentration was selected in order to ensure an excess of reagent in the reaction chamber to guarantee the reaction development.

\section{Effect of temperature on diazotization}

With the rise of temperature, diazotization speeded up. However, in theory, the diazonium salt was usually relatively stable at low temperature while it was easy to decompose at high temperature. This study tested the effect 
of temperature on the diazo reaction between 0 and $30^{\circ} \mathrm{C}$. The results showed that the absorbance was stable in the low temperature $\left(0-10{ }^{\circ} \mathrm{C}\right)$. So diazotization was carried out at $0{ }^{\circ} \mathrm{C}$ (under the condition of ice bath).

\section{Optimization for the coupling reaction}

\section{Effect of reagent concentration}

In order to assure quantitative reaction of the analyte, the effect of varying the concentration of SMZ was evaluated in the range 5.0-40.0 $\mu \mathrm{g} \mathrm{mL}^{-1}$. Steady state was reached maximum approximately from $19.2 \mu \mathrm{g} \mathrm{mL} \mathrm{mL}^{-1} \mathrm{SMZ}$ solution to the system. Absorbance of the colored product was not significantly affected by higher SMZ concentration than $19.2 \mu \mathrm{g} \mathrm{mL} \mathrm{m}^{-1}$ in both cases. For its part, $19.2 \mu \mathrm{g} \mathrm{mL}^{-1} \mathrm{SMZ}$ solution was sufficient to the present work for performing adequate analytical methods.

\section{Effect of the coupling reaction temperature}

According to the procedure, the mixture solutions of $19.2 \mu \mathrm{g} \mathrm{mL}^{-1}$ of SMZ after diazotization were cooled or heated in water bath at different temperatures. It was found that the temperature had no significant influence on the signal for the coupling reaction in the $0-30{ }^{\circ} \mathrm{C}$ range. Higher temperature resulted in a decrease of the intensity of absorbance. Consequently, we chose room temperature $\left(25.0^{\circ} \mathrm{C}\right)$ as the temperature at which the reactions were conducted.

\section{Effect of $\mathrm{pH}$ on the coupling reaction}

For coupling reaction, the value of $\mathrm{pH}$ has great impact on the absorbance intensity according to the experiment method. Coupling in alkaline medium helped to form lively anion of hydroxyl in the BPA. However, when $\mathrm{pH}$ was more than 10.0, diazoate would convert to inert trans-diazoate and did not couple. As shown in Figure 4, the absorbance increased with the rise of the $\mathrm{pH}$. When the $\mathrm{pH}$ increased at the range of 8.0-10.0, the absorbance of azo compound reached the maximum absorbance intensity and kept stable. Considering this observation, $1.0 \times 10^{-4} \mathrm{~mol} \mathrm{~L}^{-1} \mathrm{NaOH}$ solution was selected $(\mathrm{pH}=10)$.

\section{Formation and stability of azo-compound}

The results of the coupling reaction of the mixture solutions of $19.2 \mu \mathrm{g} \mathrm{mL}^{-1}$ of SMZ occurred for different times in room temperature were investigated. When the coupling reaction time occurred for above $10 \mathrm{~min}$, the absorbance increased gently. So, $10 \mathrm{~min}$ was selected as optimum. The absorbance intensity of the mixture remained stable for at least $24 \mathrm{~h}$ under sealed storage at

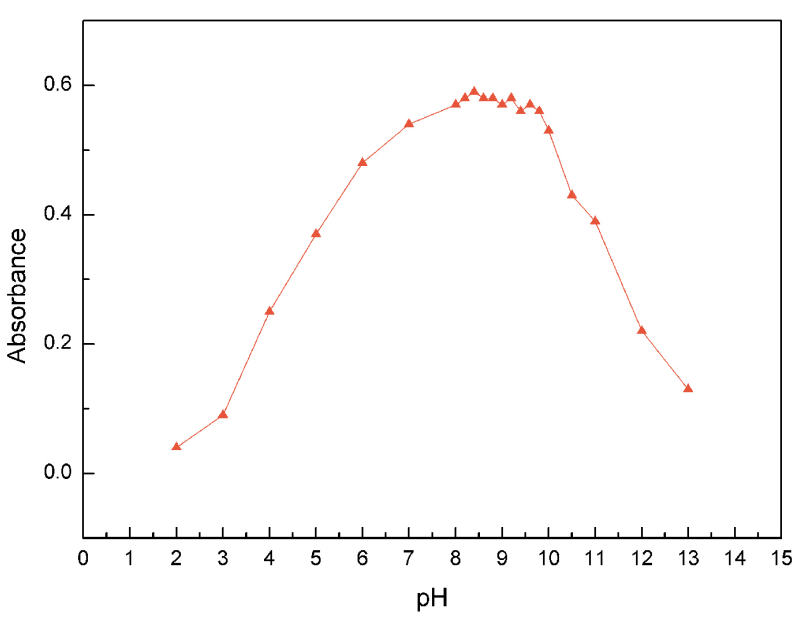

Figure 4. Effect of $\mathrm{pH}$ on the coupling reaction. Results are the average of four consecutive determinations.

room temperature. So, this system can satisfy the demand of practical stability primary.

Interference studies

The selectivity of the proposed method was studied by the effect of possible interferents on the determination of BPA. At the concentration of $4.6 \mu \mathrm{g} \mathrm{mL}^{-1} \mathrm{BPA}$, changes of absorption spectra with continuously increasing interferents concentration up to 500 ratio was investigated. As can be seen in Table 1, the concentration of added ion caused less than $\pm 5 \%$ relative error for the determination of BPA in the solution under the optimized conditions. These observations imply that the designed method could be used as a selective and efficient way for the determination of BPA in an aqueous environment.

Table 1. Tolerance to different substances in the determination of $4.6 \mu \mathrm{g} \mathrm{mL} \mathrm{L}^{-1} \mathrm{BPA}$

\begin{tabular}{lc}
\hline Species & Tolerance ratio (ion / BPA ion) \\
\hline Methanol, $\mathrm{Na}^{+}, \mathrm{K}^{+}, \mathrm{NO}_{3}^{-}, \mathrm{CN}^{-}$ & 500 \\
$\mathrm{Ca}^{2+}, \mathrm{Mg}^{2+}, \mathrm{Cl}^{-}$ & 300 \\
$\mathrm{Al}^{3+}, \mathrm{Zn}^{2+}, \mathrm{SO}_{4}^{2-}$ & 200 \\
$\mathrm{Fe}^{3+}, \mathrm{Ag}^{+}$ & 100 \\
$\mathrm{Cr}^{3+}, \mathrm{Cd}^{2+}, \mathrm{Pb}^{2+}, \mathrm{Hg}^{2+}, \mathrm{Ni}^{2+}$ & 50 \\
\hline
\end{tabular}

Linearity, limit of detection, limit of quantification and accuracy

Under the above optimum conditions, plotting the observed data versus BPA concentration, a graphical calibration curve was obtained. The calibration curve was a straight line passing through the origin. Figure 5 shows 


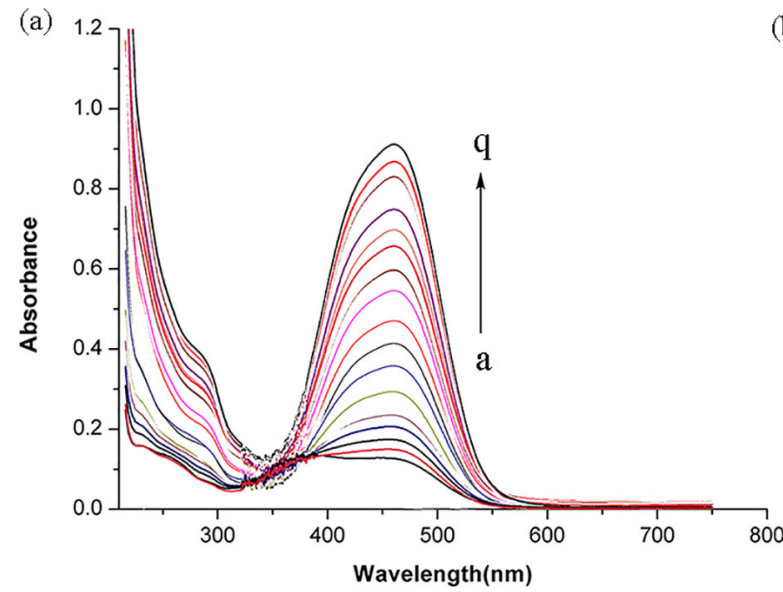

(b)

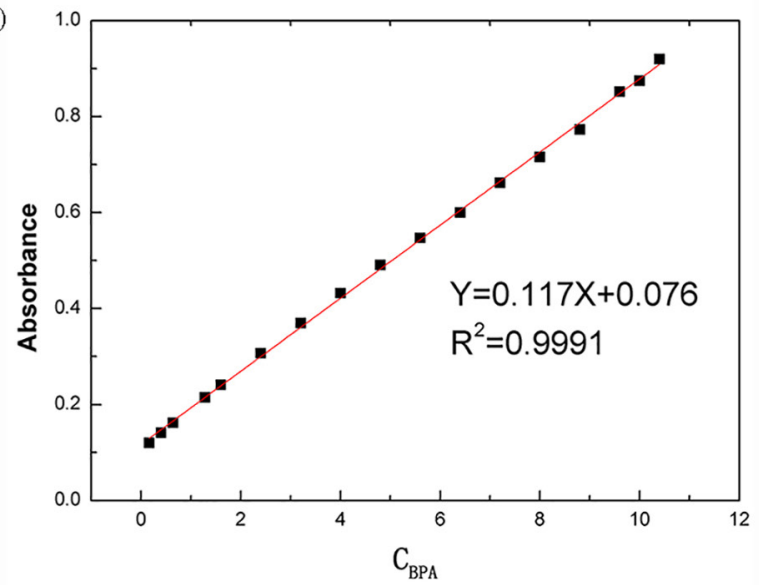

Figure 5. (a) The absorbance spectra of SMZ-BPA azo adduct in the presence of increasing concentrations of BPA. The concentration of BPA in samples a-q was $0.16,0.40,0.64,1.28,1.6,2.4,3.2,4.0,4.8,5.6,6.4,7.2,8.0,8.8,9.6,10.0$ and $10.4 \mu \mathrm{gL}^{-1}$, respectively; (b) the calibration curve of absorbance intensity versus the concentration of BPA.

that Beer's law is obeyed over the concentration range of $0.16-10.4 \mu \mathrm{g} \mathrm{mL} \mathrm{m}^{-1}$ for BPA and the linear regression equation was $\mathrm{Y}=0.076+0.117 \mathrm{X}\left(\mathrm{X}: \mu \mathrm{g} \mathrm{mL}^{-1}\right)$ with a correlation coefficient of 0.9991 . From the slope of the calibration curves, the limit of detection (LOD) and quantification (LOQ) were established. LOD and LOQ were calculated as follows (ICH Guideline 2005): ${ }^{38}$ $\mathrm{LOD}=3.3 \mathrm{~S} / \mathrm{m}, \mathrm{LOQ}=10 \mathrm{~S} / \mathrm{m}$, where $\mathrm{S}$ is the standard deviation of the data and $\mathrm{m}$ is the slope of the calibration curve. The LOD is $0.05 \mu \mathrm{g} \mathrm{mL}-1$ and LOQ is $0.15 \mu \mathrm{g} \mathrm{mL}^{-1}$. Sequentially, the accuracy of the method was determined by means of recovery test. Samples of BPA were spiked with standard solutions at three different concentrations and then analyzed using the proposed method. Good recovery percentages ranged from 99.0 to $102.3 \%$ was obtained for BPA quantification methods. Thus, the sensitivity of this method is acceptable for analytical purpose with advantages of quick, simple and sensitivity determination.

Fabrication of test strips for the detection and estimation of BPA

A test strip, similar to $\mathrm{pH}$ paper, or a pregnancy test, is widely used and highly desirable for simple and rapid monitoring. In order to facilitate the adoption of our methodology by end users, it would be advantageous to develop a test where the user adds a drop of the reaction mixture to the test strip and determines the presence of BPA by the color of the strip. To develop such a test strip, we employed a simple method of making test strips. ${ }^{39}$

A filter paper was first coated with a mixture solution of $\operatorname{SMZ}\left(19.2 \mu \mathrm{g} \mathrm{mL}^{-1}\right), \mathrm{HCl}\left(6.4 \times 10^{-2} \mathrm{~mol} \mathrm{~L}^{-1}\right)$, and $\mathrm{NaNO}_{2}$ $\left(28.0 \mu \mathrm{g} \mathrm{mL}^{-1}\right)$ in ice-water bath, which was then dried with freezer dryer. It should be immediately stored to the refrigerator when not used. Addition of a BPA test solution (in $\mathrm{NaOH}-\mathrm{CH}_{3} \mathrm{CH}_{2} \mathrm{OH}$ ) to the strip (pre-moistened with a mist of water) produces a yellow color within $1 \mathrm{~min}$. This method was able to clearly indicate the presence of BPA since the color change is very discernible from white to yellow (Figure 6). This is a simple and promising method for the semi-quantitative detection and estimation of BPA.

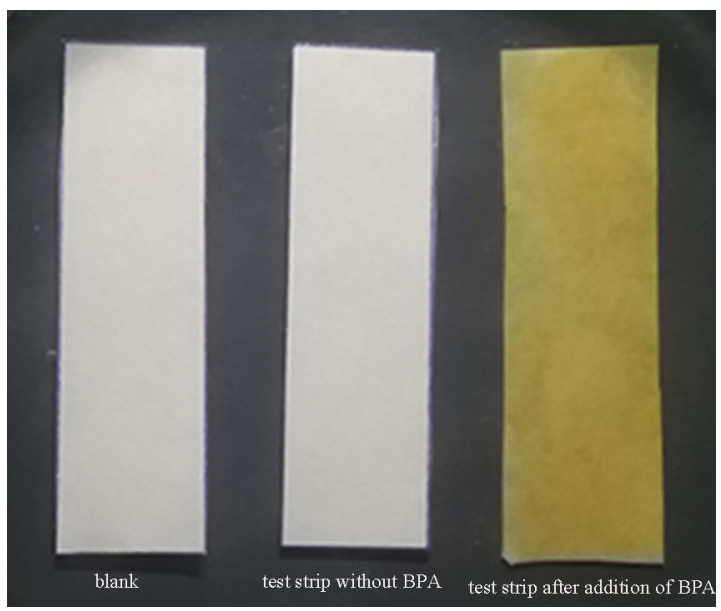

Figure 6. Test strips contain diazotizated SMZ embedded within a filter paper. The tests show a difference in color with and without BPA.

Although this is a powerful 'yes' or 'no' method for the presence of BPA, a system that produces different colors for a BPA test solution was also designed to present the same characteristics of BPA. A filter paper was first coated with a mixture solution of crystal violet lactone $(\mathrm{CVL}$, $20.0 \mu \mathrm{g} \mathrm{mL}^{-1}$ ) which was then dried with freezer dryer. Addition of a BPA test solution (in pure alcohol) to the strip did not cause any color change to the strip. However, when it was heated by a hair dryer to remove the solvent, it produces a dark blue color within $1 \mathrm{~min}$ (Figure 7), which 
further demonstrate the presence of BPA, as well as the reliability of both experimental study and analysis.

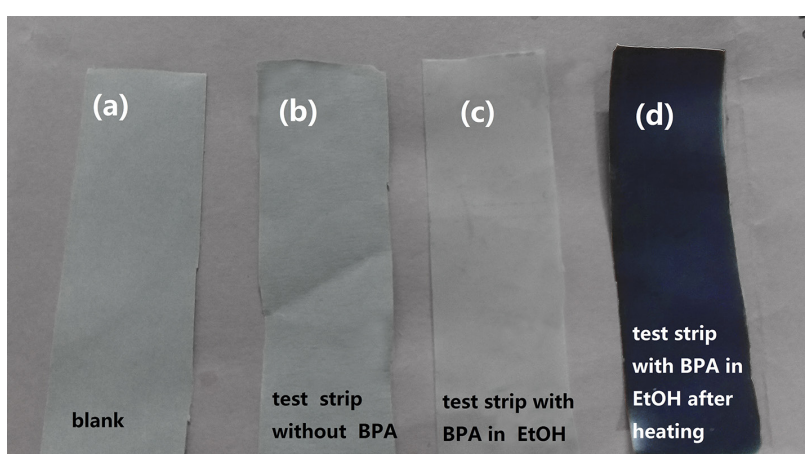

Figure 7. The tests show a difference in color with and without BPA. (a) Blank; (b) test strip containing crystal violet lactone (CVL) embedded within a filter paper; (c) test strip containing CVL embedded within a filter paper, then added BPA dissolved ethanol solution; (d) then heated to remove the solvent from it.

\section{Detection of BPA in milk and water bottle samples}

In order to demonstrate the performance of the present method, practical application of the method was assessed by detecting BPA in milk and water bottle samples via standard addition method. Certain known amounts of BPA were added into the treated sample and the recoveries were estimated to be $98.8-102.1 \%$ and $99.3-102.5 \%$ for milk and water bottle samples, respectively (Table 2). Relative standard deviations (RSDs) for 3 times parallel experiments ranged from 1.4 to $1.7 \%$ and 1.3 to $1.8 \%$ for milk and water bottle samples, respectively. These suggest that the developed method possesses potential applicability for BPA analysis in real samples. In sequence, the results were compared with those obtained from conventional HPLC (Table 3). As can be seen, good inter-day precision was established for two analytes utilizing spectrophotometric method, which was in consistency with the results obtained by HPLC method. Nevertheless, the proposed method is easier than the other protocols because it requires less manipulation and it is only necessary that the preparation of the reagent solutions be combined to the reaction. In addition, the results are precise, accurate and rapid.

\section{Conclusions}

In this paper, a novel, rapid, and easy method for quantification of BPA based on diazotizationcoupling reaction mechanism has been developed. This spectrophotometric method demonstrated to provide reproducible and accurate results using a simple, sensitive and rapid procedure. Good precision and recovery was obtained when the proposed method was applied to milk and water bottle samples. Furthermore, the HPLC method was also applied to the determination of BPA in comparison with the proposed method. The proposed method is satisfied with high sensitivity, accuracy and low detection limit. From a practical point of view, the developed method needs

Table 2. Determination of BPA in milk and water bottle samples by recovery test

\begin{tabular}{|c|c|c|c|c|}
\hline Analyte & Standard added / $\left(\mu \mathrm{g} \mathrm{mL}^{-1}\right)$ & Found / $\left(\mu \mathrm{g} \mathrm{mL} L^{-1}\right)$ & Recovery / \% & $\mathrm{RSD} / \%$ \\
\hline & 2.1 & 2.23 & 98.8 & 1.7 \\
\hline \multirow[t]{3}{*}{ Milk } & 2.9 & 3.17 & 102.1 & 1.3 \\
\hline & 3.7 & 3.89 & 101.9 & 1.4 \\
\hline & 2.1 & 2.66 & 102.5 & 1.5 \\
\hline \multirow[t]{2}{*}{ Water bottle } & 2.9 & 3.57 & 99.3 & 1.3 \\
\hline & 3.7 & 4.38 & 101.6 & 1.8 \\
\hline
\end{tabular}

Average of three determination.

Table 3. Determination of BPA samples combined with HPLC

\begin{tabular}{lcccc}
\hline Analyte & Standard added $\left./(\mu \mathrm{g} \mathrm{mL})^{-1}\right)$ & Found / $\left.(\mu \mathrm{g} \mathrm{mL})^{-1}\right)$ & Recovery / \% & RSD / \% \\
\hline \multirow{3}{*}{ Milk } & 2.1 & 2.36 & 104.2 & 2.4 \\
& 2.9 & 3.21 & 103.7 & 2.1 \\
\hline \multirow{2}{*}{ Water bottle } & 3.7 & 3.83 & 103.6 & 1.5 \\
& 2.1 & 2.60 & 101.7 & 1.9 \\
\hline
\end{tabular}

Average of three determination. 
minimum sample treatment, which allowed us to achieve a high analytical productivity. These advantages make the proposed method very suitable for routine analysis of BPA in quality control laboratories.

\section{References}

1. Liu, G. L.; Chen, Z.; Jiang, X. Y.; Feng, D. Q.; Zhao, J. Y.; Fan, D. H.; Wang, W.; Sens. Actuators, B 2016, 228, 302.

2. Huang, J. D.; Zhang, X. M.; Lin, Q.; He, X. R.; Xing, X. R.; Huai, H. X.; Lian, W. J.; Zhu, H.; Food Control 2011, 22, 786.

3. Tan, F.; Cong, L.; Li, X.; Zhao, Q.; Zhao, H.; Quan, X.; Chen, J.; Sens. Actuators, B 2016, 233, 599.

4. Wang, H. Y.; Lee, A. W. M.; Shuang, S. M.; Choi, M. M. F.; Microchem. J. 2008, 89, 90.

5. Vinas, P.; Campillo, N.; Martinez-Castillo, N.; HernandezCordoba, M.; Anal. Bioanal. Chem. 2010, 397, 115.

6. Wetherill, Y. B.; Akingbemi, B. T.; Kanno, J.; McLachlan, J. A.; Nadal, A.; Sonnenscheing, C.; Watson, C. S.; Zoeller, R. T.; Belcher, S. M.; Reprod. Toxicol. 2007, 24, 178.

7. Kamalabadi, M.; Mohammadi, A.; Alizadeh, N.; Talanta 2016, $156,147$.

8. Cao, X. Y.; Shen, F.; Zhang, M. W.; Bie, J. X.; Liu, X.; Luo, Y. L.; Guo, J. J.; Sun, C. Y.; RSC Adv. 2014, 4, 16597.

9. Calafat, A. M.; Kuklenyik, Z.; Reidy, J. A.; Caudill, S. P.; Ekong, J.; Needham, L. L.; Environ. Health Perspect. 2005, 113, 391.

10. Schonfelder, G.; Wittfoht, W.; Hopp, H.; Talsness, C. E.; Paul, M.; Chahoud, I.; Environ. Health Perspect. 2002, 110, 703.

11. Yan, X. P.; Zhou, C. Q.; Yan, Y.; Zhu, Y.; Electroanalysis 2015, 27, 2718.

12. Hengstler, J. G.; Foth, H.; Gebel, T.; Kramer, P. J.; Lilienblum, W.; Schweinfurth, H.; Volkel, W.; Wollin, K. M.; Gundert-Remy, U.; Crit. Rev. Toxicol. 2011, 41, 263.

13. Hass, U.; Christiansen, S.; Boberg, J.; Rasmussen, M. G.; Mandrup, K.; Axelstad, M.; Andrology 2016, 4, 594.

14. Ballesteros-Gomez, A.; Rubio, S.; Perez-Bendito, D.; J. Chromatogr. A 2009, 1216, 449.

15. Watabe, Y.; Kondo, T.; Morita, M.; Tanaka, N.; Haginaka, J.; Hosoya, K.; J. Chromatogr. A 2004, 1032, 45.

16. Yazdinezhad, S. R.; Ballesteros-Gomez, A.; Lunar, L.; Rubio, S.; Anal. Chim. Acta 2013, 778, 31.

17. Wille, K.; De Brabander, H. F.; De Wulf, E.; Van Caeter, P.; Janssen, C. R.; Vanhaecke, L.; TrAC, Trends Anal. Chem. 2012, $35,87$.

18. Deceuninck, Y.; Bichon, E.; Durand, S.; Bemrah, N.; Zendong, Z.; Morvan, M. L.; Marchand, P.; Dervilly-Pinel, G.; Antignac, J. P.; Leblanc, J. C.; Le Bizec, B.; J. Chromatogr. A 2014, 1362, 241.
19. De Meulenaer, B.; Baert, K.; Lanckriet, H.; Van Hoed, V.; Huyghebaert, A.; J. Agric. Food Chem. 2002, 50, 5273.

20. Ragavan, K. V.; Rastogi, N. K.; Thakur, M. S.; TrAC, Trends Anal. Chem. 2013, 52, 248.

21. Mita, D. G.; Attanasio, A.; Arduini, F.; Diano, N.; Grano, V.; Bencivenga, U.; Rossi, S.; Amine, A.; Moscone, D.; Biosens. Bioelectron. 2007, 23, 60.

22. Chen, X. L.; Wang, C.; Tan, X. M.; Wang, J. X.; Anal. Chim. Acta 2011, 689, 92.

23. Chung, E.; Jeon, J.; Yu, J.; Lee, C.; Choo, J.; Biosens. Bioelectron. 2015, 64, 560.

24. Mei, Z. L.; Chu, H. Q.; Chen, W.; Xue, F.; Liu, J.; Xu, H. N.; Zhang, R.; Zheng, L.; Biosens. Bioelectron. 2013, 39, 26.

25. Zhu, L. L.; Cao, Y. H.; Cao, G. Q.; Biosens. Bioelectron. 2014, $54,258$.

26. Huang, N.; Liu, M. L.; Li, H. T.; Zhang, Y. Y.; Yao, S. Z.; Anal. Chim. Acta 2015, 853, 249.

27. Darwish, H. W.; Elzanfaly, E. S.; Saad, A. S.; Abdelaleem, A. E. B.; Spectrochim. Acta, Part A 2016, 169, 50.

28. Mirazizi, F.; Bahrami, A.; Haghbeen, K.; Shahbani Zahiri, H.; Bakavoli, M.; Legge, R. L.; J. Enzyme Inhib. Med. Chem. 2016, 31,1162 .

29. Pyrzynska, K.; Microchim. Acta 2005, 149, 159.

30. Cao, G. P.; Zhuang, Y. F.; Liu, B. L.; S. Afr. J. Chem. 2014, 67, 99.

31. Poorahong, S.; Thammakhet, C.; Thavarungkul, P.; Kanatharana, P.; J. Environ. Sci. Health, Part A 2013, 48, 242.

32. Zhang, K.; Hu, Y.; Li, G.; Talanta 2013, 116, 712.

33. Filik, H.; Giray, D.; Ceylan, B.; Apak, R.; Talanta 2011, 85, 1818.

34. Zarchi, M. A. K.; Ebrahimi, N.; J. Appl. Polym. Sci. 2011, 121, 2621.

35. Ahmad, A. K.; Hassan, Y. I.; Bashir, W. A.; Analyst 1986, 111, 243.

36. Yan, Z.; Hu, L.; Nie, L.; Lv, H.; Spectrochim. Acta, Part A 2011 , $79,661$.

37. Freitas, S. K. B.; da Silva, V. L.; Araujo, A. N.; Montenegro, M.; Reis, B. F.; Paim, A. P. S.; J. Braz. Chem. Soc. 2011, 22, 279.

38. ICH Guideline; Validation of Analytical Procedures: Text and Methodology Q2 (R1), 2005. Available at http://www.ich.org/ products/guidelines/quality/article/quality-guidelines.html, accessed in December 2016.

39. Joy, A.; Anim-Danso, E.; Kohn, J.; Talanta 2009, 80, 231.

Submitted: October 25, 2016

Published online: December 20, 2016 